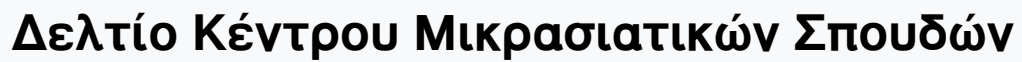

Tó 10 (1993)

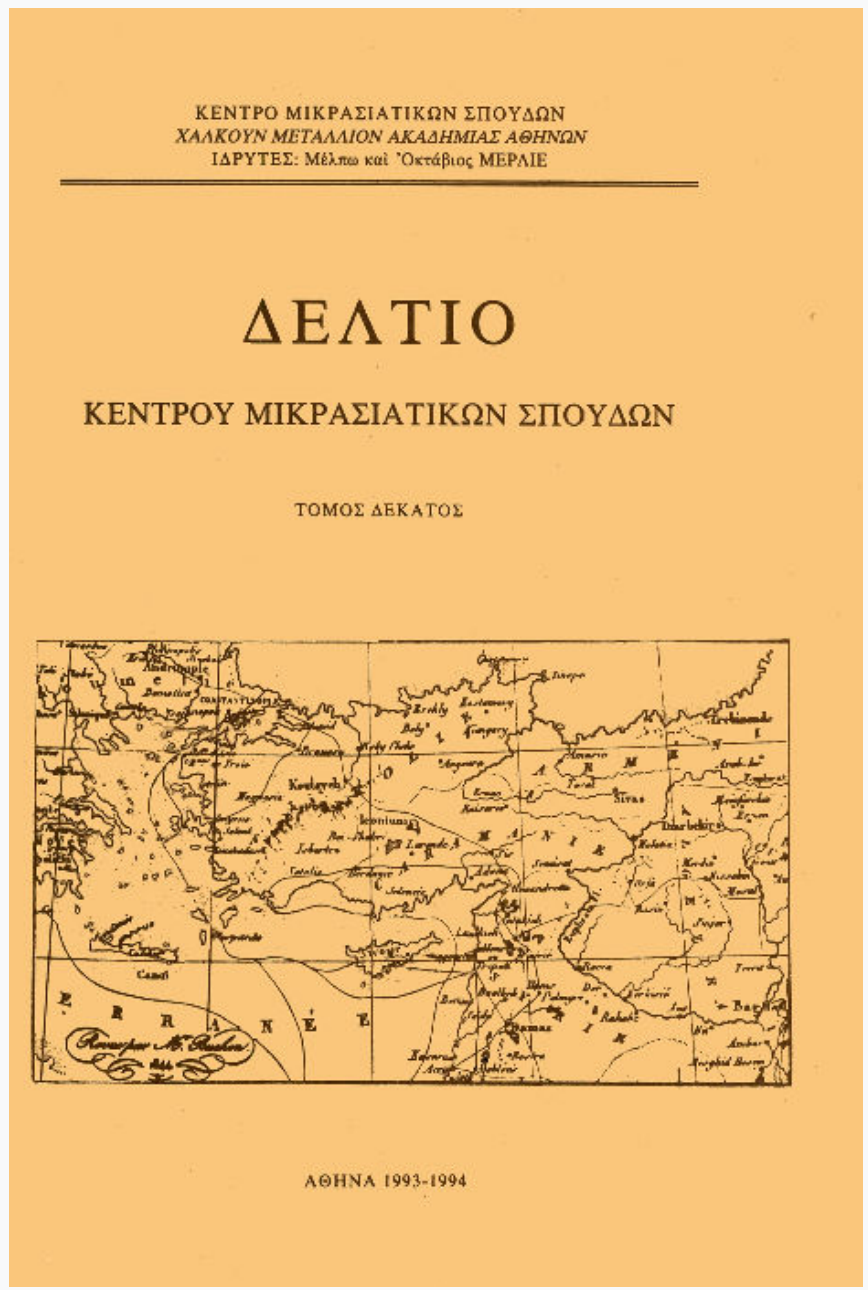

\section{Suraiya Faroqhi, Herrscher uber Mecca, Die Geschichte der Pilgerfahrt}

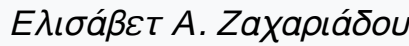

doi: $10.12681 /$ deltiokms.106

\section{(c) (i) (9)}

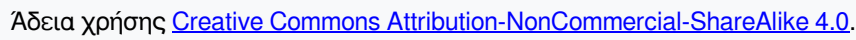

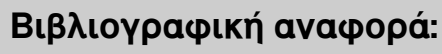

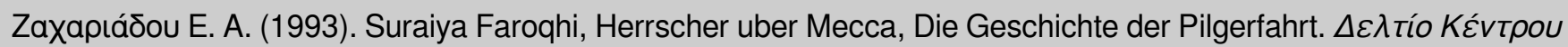

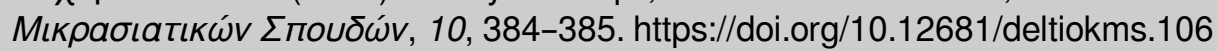




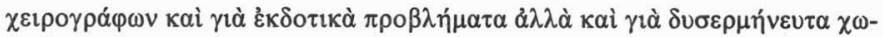

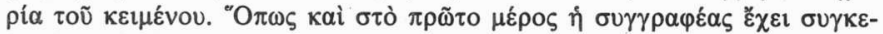

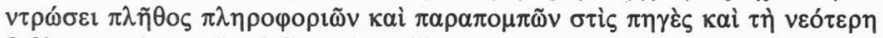

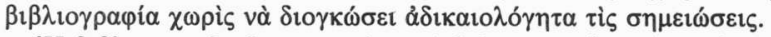

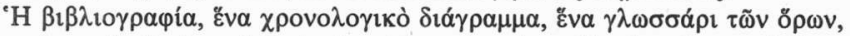

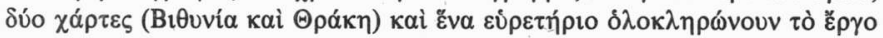

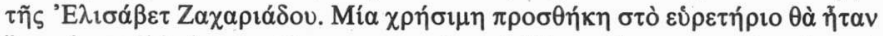

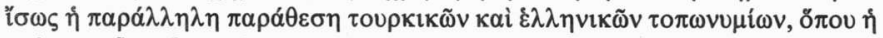

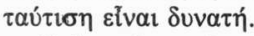

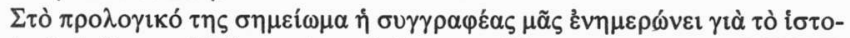

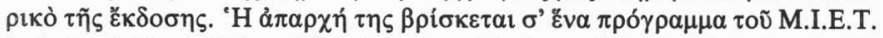

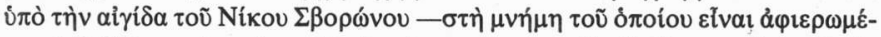

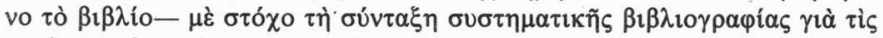

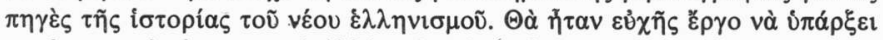

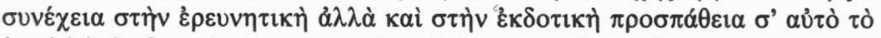

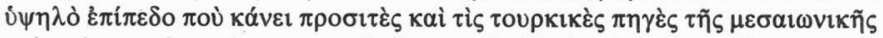

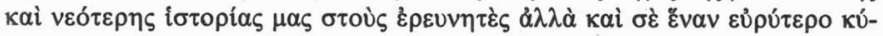
$\kappa \lambda \circ$ åv $\alpha \gamma v \omega \sigma \tau \tilde{\nu} v$.

MAPIA $\Sigma T A \Sigma I N O \Pi O Y \Lambda O Y$

Süraiya Faroqhi, Herrscher über Mecca, Die Geschichte der Pilgerfahrt, Mó-

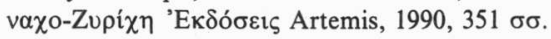

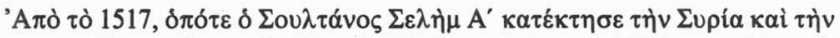

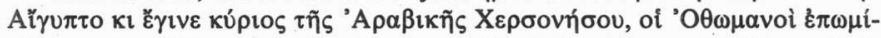

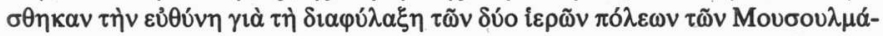

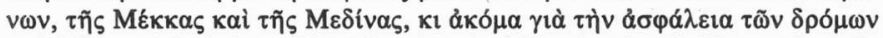

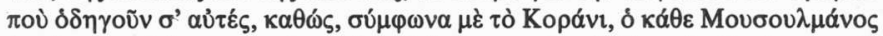

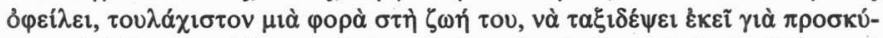

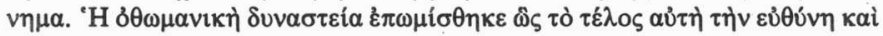

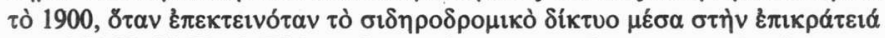

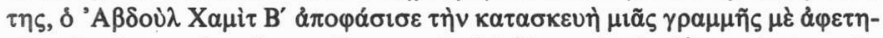

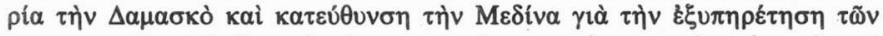

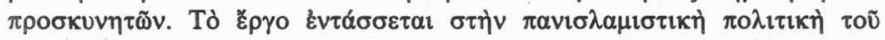

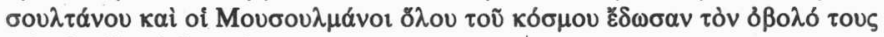

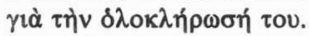

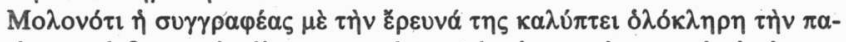

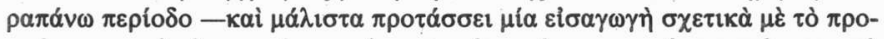

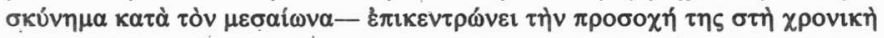




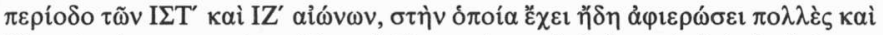

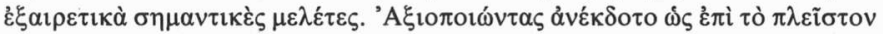

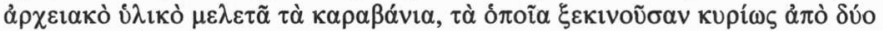

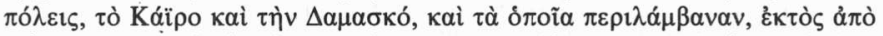

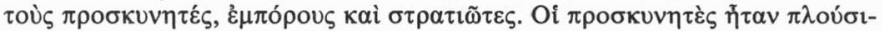

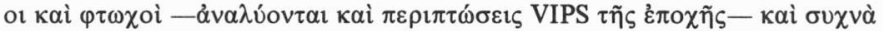

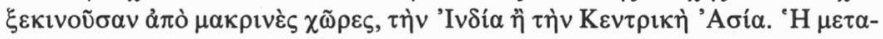

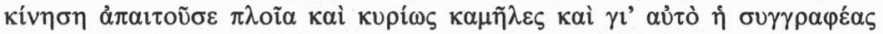

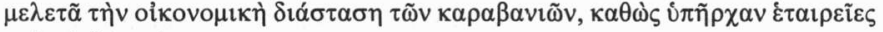

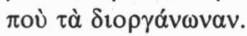

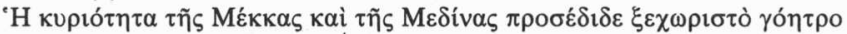

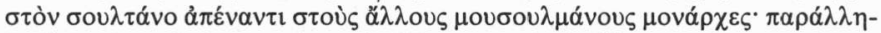

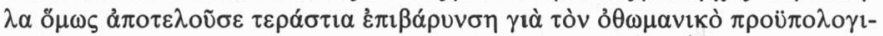

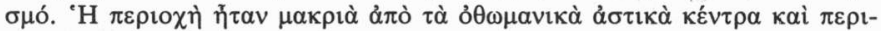

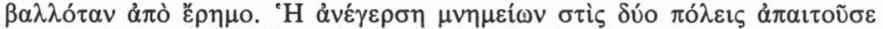

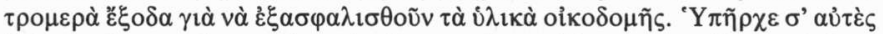

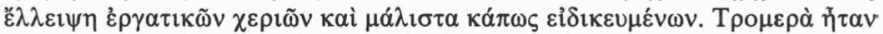

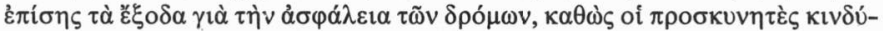

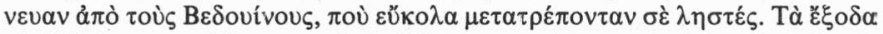

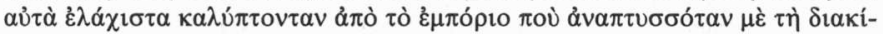

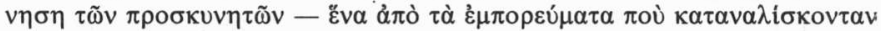

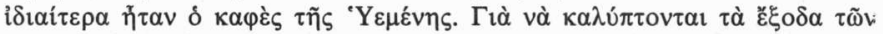

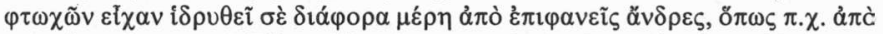

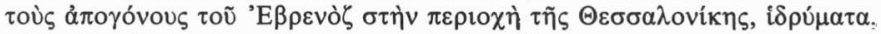

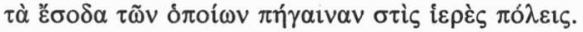

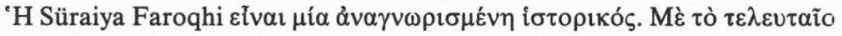
$\tau \eta \varsigma \alpha$ นù

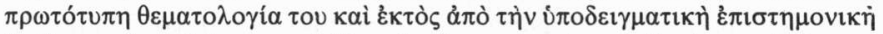

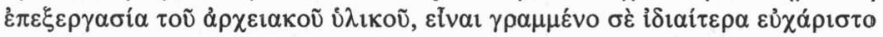

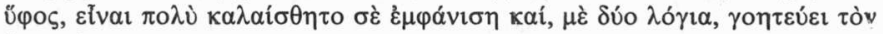

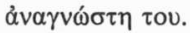

